\title{
BUDAYA SUKU BUGIS SEBAGAI DAYA TARIK WISATA DI PANTAI BUNG JABE KARIMUNJAWA
}

\author{
Citra Unik Mayasari \\ Dosen AKPAR BSI Yogyakarta \\ NIDN : 0511039201 \\ Email: citra.cyu@bsi.ac.id
}

Oleh

\author{
Yulianto \\ Dosen AKPAR BSI Yogyakarta \\ NIDN: 0517077602 \\ Email: yulianto.ylt@bsi.ac.id
}

\begin{abstract}
Indonesia is consist of several islands and have various ethnic, tribal and cultural, so it has great potential in the world of tourism especially cultural tourism. Almost all islands or regions of Indonesia have a culture that can be used as a tourist attraction. One of them is the culture of bugis tribe used as a tourist attraction in Bunga Jabe Karimunjawa. The manager of Bunga Jabe Karimunjawa is currently do development of tourist attraction by carrying the theme of bugis tribal culture as a tourist attraction and also as the way to preserve the culture of bugis tribe on Bunga Jabe Karimunjawa. In this research, researchers used qualitative naturalistic methods because in this study conducted on natural conditions and researchers as the key instrument. Data collection techniques use observation, interview and documentation techniques. Some cultures of bugis tribe used as a tourist attraction at Bunga Jabe Karimunjawa beach are local language or bugis language, bugis traditional art of Pecak Silat Baruga and Paduppa Dance, custom homes of bugis tribe or stlit house, dwarf house as an accommodation and bugis typical food.
\end{abstract}

Keywords: Tourism, Bugis Tribe, Tourist Attraction, Culture

\section{PENDAHULUAN}

Kepariwisataan di Indonesia di arahkan sebagai sektor andalan dalam mendorong pertumbuhan ekonomi untuk meningkatkan pendapatan daerah ataupun untuk meningkatkan perekonomian masyarakat dan menambah lapangan pekerjaan. Pariwisata di Indonesia kini sangat berkembang dengan pesat, beberapa diantaranya adalah wisata alam dan wisata budaya. Pariwisata di Indonesia terkenal dengan pariwisata yang memiliki banyak keanekaragaman dan keunikan budaya.

Indonesia terdiri dari beberapa kepulauan dan memiliki banyak suku di dalamnya, sehingga Indonesia berpotensi besar dalam dunia pariwisata khususnya di bidang wisata budaya, karena Indonesia memiliki banyak kekayaan etnis dan budaya yang masing-masing memiliki ciri khas tersendiri. Hampir semua kepulauan atau daerah yang berada di Indonesia memiliki budaya yang bisa dijadikan sebagai potensi daya tarik wisata di daerah tersebut. Salah satunya adalah budaya suku bugis yang dijadikan sebagai daya tarik wisata di Pantai Bunga Jabe yang terletak di Pulau Karimunjawa.

Karimunjawa adalah kepulauan di laut jawa yang termasuk dalam Kabupaten Jepara Provinsi Jawa Tengah. Karimunjawa kini dikembangkan menjadi pesona wisata taman laut atau wisata bahari yang mulai banyak digemari wisatawan lokal maupun wisatawan 
mancanegara. Karimunjawa terdiri dari 27 pulau namun 22 pulau diantaranya tidak berpenghuni. Pulau Kemujan adalah salah satu pulau yang berpenghuni. Pulau kemujan juga banyak memiliki potensi wisata, salah satunya adalah Pantai Bunga Jabe.

Pantai Bunga Jabe terletak di desa Kemujan di sebelah timur bandara Dewadaru. Pantai Bunga Jabe ini masih cukup asing untuk beberapa wisatawan. Masyarakat yang tinggal di sekitar Pantai Bunga Jabe ini terdiri dari 3 suku yaitu Suku Bugis, Suku Jawa dan Suku Madura, tetapi konsep Pantai Bunga Jabe ini lebih mengusung tema tentang Suku Bugis. Pantai Bunga Jabe ini memiliki daya tarik wisata yang berbeda dengan pantai yang lain. Konsep pantai dengan perpaduan budaya suku bugis, seni dan keindahan alamnya sangat melekat kuat, sehingga menciptakan kesan dan pengalaman tersendiri bagi para wisatawan yang berkunjung di pantai ini. Pengelola pantai Bunga Jabe saat ini sedang melakukan pengembangan atau perbaikan fasilitas dengan mengusung tema budaya suku bugis sebagai daya tarik wisata dan juga sebagai upaya pelestarian budaya suku bugis di Pantai Bunga Jabe Karimunjawa. Dari latar belakang diatas penulis ingin meneliti tentang Budaya Suku Bugis Sebagai Daya Tarik Wisata Di Pantai Bunga Jabe Karimunjawa.

\section{LITERATURE REVIEW}

\section{Pengertian Pariwisata}

Goelder dalam Hadiwijoyo (2012) mengatakan bahwa pariwisata adalah perjalanan dari satu tempat ke tempat lain dan bersifat sementara, dilakukan perorangan ataupun kelompok sebagai usaha mencari keseimbangan, keserasian dalam dimensi sosial budaya dan ilmu.

Menurut Undang-undang nomor 10 tahun 2009 tentang Kepariwisataan, yang dimaksud dengan pariwisata adalah berbagai macam kegiatan wisata dan didukung berbagai fasilitas serta layanan yang disediakan oleh masyarakat, pengusaha, Pemerintah, dan Pemerintah Daerah.

Sementara Spillane (2001) menyatakan pariwisata adalah kegiatan melakukan perjalanan dengan tujuan untuk mendapatkan kenikmatan, mencari kepuasan, mengetahui sesuatu, memperbaiki kesehatan, menikmati olahraga atau istirahat, menunaikan tugas, dan berziarah.

\section{Jenis pariwisata}

Dalam pariwisata terdapat beberapa jenis pariwisata, salah satunya adalah wisata maritime (marina) atau bahari. Menurut Pendit (2006), wisata bahari adalah jenis wisata yang banyak dikaitkan dengan kegiatan olahraga air, lebih-lebih di danau, bengawan, pantai, teluk atau laut lepas seperti memancing, menyelam, berselancar.

\section{Daya tarik wisata}

Daya Tarik Wisata Menurut Yoeti (2006) di bagi menjadi empat bagian;

1. Daya tarik wisata alam, yang meliputi pemandangan alam, laut, pantai dan pemandangan alam lainnya.

2. Daya tarik wisata dalam bentuk bangunan, yang meliputi bersejarah dan modern, monument, peninggalan arkeologi, lapangan golf, took dan tempat perbelanjaan lainnya.

3. Daya tarik wisata budaya yang meliputi sejarah, faktor, agama, seni, teater, hiburan dan museum.

4. Daya tarik wisata sosial, yang meliputi cara hidup masyarakat setempat, bahasa, kegiatan sosial masyarakat, fasilitas dan pelayanan masyarakat.

Menurut Yoeti (2002) Terdapat (tiga) unsur penting suatu daya tarik wisata, yaitu:

1. Something to do (sesuatu untuk dilakukan). Artinya selain banyak yang 
dapat dilihat dan disaksikan di tempat tersebut, harus pula disediakan fasilitas rekreasi dan hiburan yang dapat membuat mereka betah tinggal lebih lama ditempat itu.

2. Something to see(sesuatu untuk dilihat). Artinya ditempat tersebut harus ada daya tarik wisata dan atraksi wisata yang berbeda dengan apa yang dimiliki oleh daerah lain. Dengan kata lain daerah itu harus mempunyai daya tarik yang khusus, disamping itu juga mempunyai atraksi wisata yang dapat disajikan "entertainments" atau hiburan.

3. Something to buy (sesuatu untuk dibeli). Artinya ditempat tersebut harus tersedia fasilitas untuk berbelanja, terutama barang-barang souvenir/ cinderamata dan untuk kuliner sebagainya.

Menurut Damanik dan Weber (2006), daya tarik wisata yang baik sangat terkait dengan empat hal, yakni memiliki keunikan, orijinalitas, otentisitas dan keragaman. Keunikan di artikan sebagai kombinasi kelangkaan dan kekhasan yang melekat pada suatu daya tarik wisata. Orijinalitas (keaslian) mencerminkan keaslian atau kemurnian, yakni seberapa jauh produk tidak terkontaminasi atau tidak mengadopsi nilai yang berbeda dengan nilai aslinya. Otentisitas mengacu pada keaslian, otentisitas biasanya di kaitkan dengan eksotisme budaya sebagai daya tarik wisata dan merupakan kategori nilai yang memadukan sifat alamiah, eksotisme dan bersahaja.

Menurut Marpaung (2002) pengertian daya tarik wisata adalah suatu bentukan dan atau aktivitas dan fasilitas yang berhubungan, yang dapat menarik minat wisatawan ataupengunjung untuk datang ke kesuatu daerah/tempat tertentu.

\section{Kebudayaan dan pariwisata}

Dua hal yang akan di bicarakan dalam bagian ini, yaitu (a) wisata budaya sebagai suatu jenis wisata; dan (b) pengaruh pariwisata terhadap kebudayaan. Wisata budaya diartikan sebagai jenis kegiatan pariwisata yang objeknya adalah kebudayaan. Daya tarik wisata budaya dapat berkisar beberapa hal seperti kesenian, tata busana, boga, upacara adat. Objek - objek tersebut di kemas khusus agar lebih menarik untuk wisatawan (Yoeti, 2006).

Mengenai pengaruh pariwisata terhadap kebudayaan pada masyarakat tuan rumah dapat di bedakan dua perkara, yaitu; (a) pengaruh dalam kehidupan ekonomi apabila kegiatan pariwisata itu dapat meningkatkan kesempatan kerja dan tingkat kemakmuran; dan (b) pengaruh kehadiran wisatawan mancanegara dengan kebiasaan dan busananya yang sebenarnya asing bagi masyarakat tuan rumah (Yoeti, 2006).

\section{METODE PENELITIAN}

Penelitian ini menggunakan metode kualitatif naturalistik karena pada penelitian ini dilakukan pada kondisi yang alamiah dan peneliti sebagai instrumen kuncinya. Metode kualitatif sebagai prosedur penelitian yang menghasilkan data deskriptif berupa katakata tertulis atau lisan (Moeleong, 2006). Penelitian ini dilakukan di Pantai Bunga Jabe yang beralamatkan di Jl. Karimun Adil Telaga RT/RW: 03/03 Kemujan Karimunjawa.

Sejumlah metode pengumpulan data yang digunakan dalam penelitian adalah : (1) Observasi, menurut Nasution dalam Sugiyono (2011), observasi adalah dasar semua ilmu pengetahuan. Peneliti melakukan observasi langsung di sekitar pantai bunga jabe. Dalam penelitian ini menggunakan 
tehnik observasi terus terang atau tersamar yaitu mereka orang yang akan di teliti mengetahui sejak awal hingga akhir tentang aktivitas peneliti. (2) Wawancara, menurut Esterberg dalam Sugiyono (2011), wawancara adalah merupakan pertemuan dua orang untuk bertukar informasi dan ide melalui tanya jawab, sehingga dapat dikonstruksikan makna dalam suatu topik tertentu. Dalam penelitian ini peneliti menggunakan metode wawancara semiterstruktur tujuannya untuk menemukan permasalahan lebih terbuka, dimana pihak yang di wawancara di minta pendapat dan ide-idenya. Peneliti melakukan langsung tanya jawab dengan pengelola pantai bunga jabe, wisatawan dan masyarakat sekitar. Wawancara ini dilakukan bertujuan untuk mendapatkan informasi tentang apa saja yang menjadi daya tarik wisata di Pantai Buga Jabe dan apa saja upaya yang sudah dilakukan untuk pelestarian budaya dan lingkungan, dan (3) Dokumentasi, pada penelitian ini peneliti menggunakan metode pengumpulan data dengan dokumen. Dokumen merupakan catatan peristiwa yang sudah berlalu. Dokumen bisa berbentuk gambar, tulisan, atau karya-karya monumental seseorang. Studi dokumen merupakan pelengkap dari penggunaan metode observasi dan wawancara dalam penelitian kualitatif (Sugiyono, 2011). Peneliti mengumpulkan data dari beberapa literature, jurnal, serta mengumpulkan data- data yang ada di Pantai Bunga Jabe seperti foto.

\section{HASIL PENELITIAN DAN PEMBAHASAN}

\section{Sejarah Pantai Bunga Jabe}

Pantai Bunga jabe mulai di bangun pada tahun 2012 tepatnya pada tanggal 02 November 2012. Berangkat dari sebuah kekhawatiran akan maraknya penjualan tanah ketika itu. Pada akhirnya rencana membuat sebuah tempat untuk bersantai atau hanya untuk sekedar main saja, yang nantinya akan menjadi contoh untuk para masyarakat sekitar bahwa tanpa menjual tanah kita bisa mendapatkan pendapatan atau income. Nama "Bunga Jabe" sendiri di ambil dari bahasa Bugis yang artinya "Putri Malu", tetapi kata "Jabe" sendiri berarti manja dalam bahasa Bugis. Yang harapannya adalah siapaun yang datang bisa memanjakan mata, pikiran, dan apa saja yang mau dimanjakan. Selain itu dulu juga banyak tumbuh bunga jabe (bunga putri malu) di sekitar pantai, dan bunga ini juga sangat atraktif sudah jarang di temukan di tempat lain.

\section{Sejarah Singkat Suku Bugis di Karimunjawa}

Pada tahun 1948 itu H.M. Amin beserta saudaranya berjumlah 7 orang berlayar dari perairan kepulauan Masalembu menuju Karimunjawa. Latok H.M. Amin menjadi pemimpin dalam perjalanan tersebut, 7 orang tersebut merupakan keluarga besar dari H.M. Amin yaitu adek dan keponakannya. Setelah sampai di karimun kapal memutari pulau-pulau besar di karimun hingga 2 kali, dan akhirnya latok Amin memberikan aba-aba untuk berhenti. Ketika latok amin memberikan aba-aba untuk berhenti, posisi kapal tepat berada di daerah Telaga sebelah barat. Latok amin bukanlah orang pertama yang mencoba untuk bertahan di sini. Sebelum latok Amin ada 2 generasi yang pernah mencoba bertahan hidup di Telaga ini dengan bercocok tanam. Generasi pertama mencoba bercocok tanam tetapi gagal bertahan karena serangan hama. Kemudian generasi kedua juga gagal bertahan karena hal yang sama yaitu serangan hama seperti menjangan, monyet, landak dan hama yang lain. Pada akhirnya generasi ke dua pindah ke daerah lain seperti Cikmas, Nyamplungan. Sampai akhirnya Latok Amin sebagai generasi ketiga yang mencoba bertahan hidup di telaga ini berhasil 
bertahan dengan bercocok tanam dan Latok Amin kembali ke Masalembu untuk mengambil pasukan sejumlah 40 orang untuk membantu bercocok tanam disini hingga saat ini. Ketika H.M. Amin meninggal di makamkan di sekitar Masjid Telaga, hingga sekarang makam tersebut masih terawat.

\section{Budaya Suku Bugis Sebagai Daya Tarik Wisata Di Pantai Bunga Jabe Karimunjawa}

Pantai bunga jabe ini menawarkan wisata alam yang berbeda dengan pantai yang lain. Pantai bunga jabe adalah salah satu wisata pantai yang menawarkan keindahan alam berserta suku dan budayanya yang kental. Wisatawan yang berkunjung akan di manjakan dengan keindahan alam dan kekayaan budaya suku bugis di pantai ini, sehingga para wisatawan yang berkunjung di pantai ini akan merasakan sensasi yang berbeda ketika berkunjung. Beberapa budaya suku bugis yang menjadi daya tarik wisata di Pantai Bunga Jabe Karimunjawa adalah:

\section{Bahasa Daerah (Bahasa Bugis)}

Salah satu daya tarik wisata yang ada di Pantai Bunga Jabe ini yang sangat menarik adalah bahasa daerahnya yaitu bahasa bugis. Banyak para wisatawan yang tertarik dan ingin belajar bahasa bugis ketika sedang berwisata di pantai ini. Di era modernisasi ini bahasa daerah semakin tenggelam di telan waktu. Pada kenyataannya pamor bahasa daerah sekarang sudah kalah jauh di bandingkan dengan bahasa Indonesia yang menjadi bahasa nasional kita dan bahasa Inggris yang di juluki sebagai bahasa internasional. Tetapi masyarakat sekitar Pantai Bunga Jabe dalam kehidupan seharihari mereka selalu menggunakan bahasa bugis, selain di jadikan sebagai sebuah daya tarik wisata bahasa bugis ini di gunakan setiap hari oleh masyarakat sebagai salah satu upaya pelestarian budaya suku bugis. Mereka bangga menggunakan bahasa daerah karena bagi mereka bahasa daerah adalah identitas suku mereka.

\section{Kesenian Suku Bugis}

a. Pencak Silat Baruga

Pencak Silat Baruga adalah salah satu kesenian suku bugis yang ada di Pantai Bunga Jabe. Pencak silat baruga sejatinya bukan pencak silat untuk bertarung, tetapi pencak silat baruga ini lebih menekankan pada keindahan tarian dengan perpaduan musik dan seni bela diri. Pencak silat baruga ini adalah pencak silat untuk penjemputan atau penyambutan tamu. Biasanya digunakan dalam penyambutan pada acara adat suku bugis seperti prosesi lamaran ataupun pesta pernikahan.

b. Tari Paduppa

Tari Paduppa adalah salah satu kesenian tarian suku bugis yang ada di Pantai Bunga Jabe. Tari paduppa adalah sebuah jenis tarian yang di lakukan suku bugis untuk menyambut tamu. Tari paduppa ini dapat di katakan sebagai tari selamat datang dari suku bugis bagi para tamu sebagai bentuk penghormatan. Gerakan pada tarian paduppa ini sangat lembut dan luwes dengan perpaduan musik yang indah sehingga sangat menarik perhatian wisatawan.

\section{Rumah Adat Suku Bugis}

Pantai Bunga Jabe ini memiliki daya tarik wisata yang berbeda dengan pantai yang lain. Konsep pantai dengan nuansa seni suku bugis di padukan dengan keindahan alam sangat terasa sekali di pantai ini. Di pantai bunga jabe ini terdapat bangunan rumah panggung yaitu rumah khas suku bugis yang di sewakan sebagai home stay. Tarif menginap di rumah panggung ini relatif murah satu 
malam Rp 300.000,00 sudah termasuk morning cake (kue dan teh) untuk 2 orang.

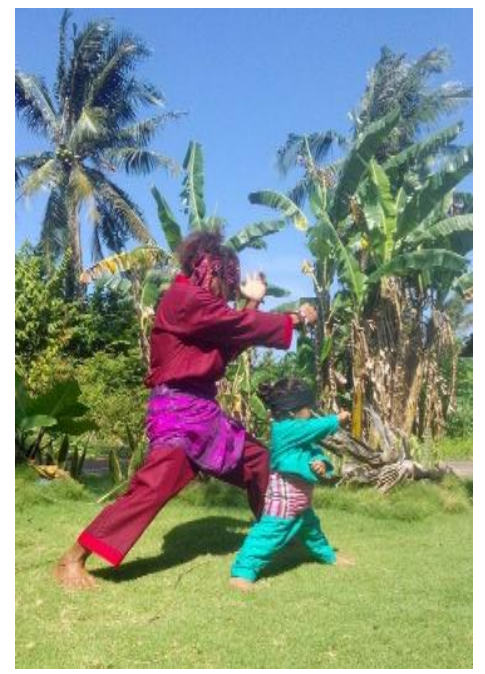

Gambar 1. Pencak Silat Baruga

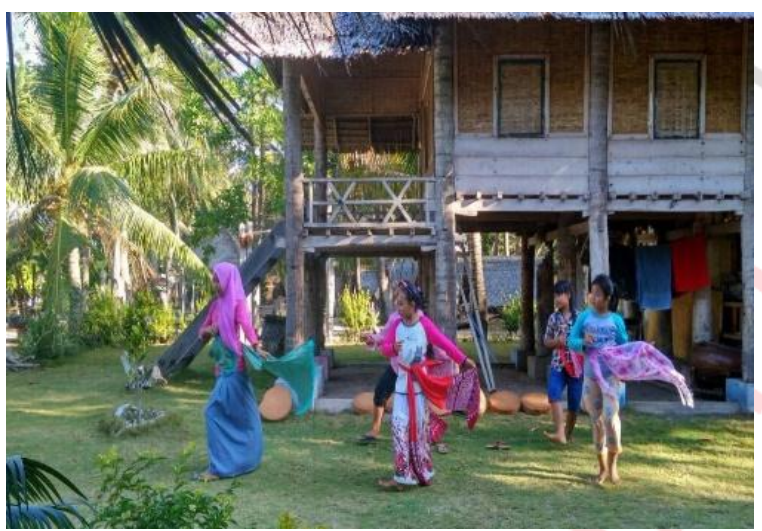

Gambar 2. Tari Paduppa

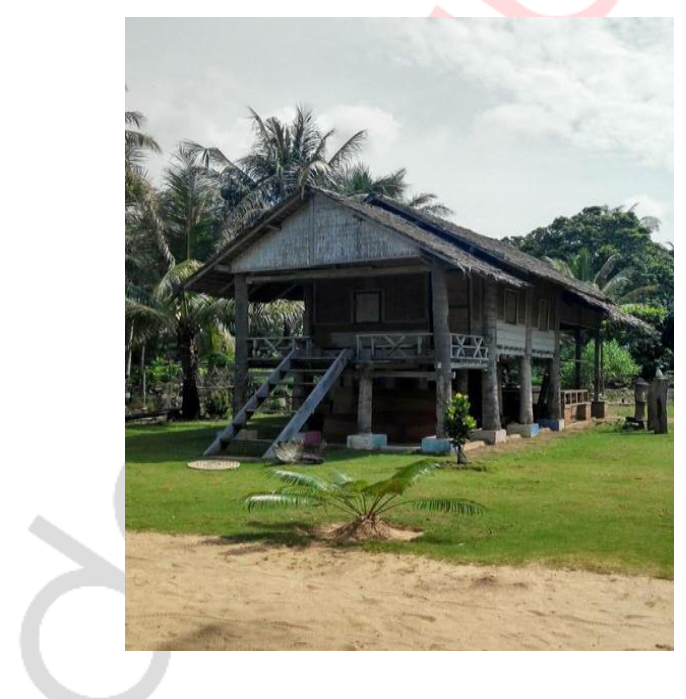

Gambar 3. Rumah Panggung
Karakteristik fisik rumah panggung suku bugis ini biasanya di buat tidak permanen sehingga mudah di bongkar dan di pindah. Rumah panggung terdiri dari kayu dengan atap berlereng dua dan kerangkanya berbentuk huruf " $\mathrm{H}$ " yang terdiri dari tiang dan balok, rumah panggung ini di rakit tanpa menggunakan paku. Rumah bugis atau rumah panggung di pantai Bunga Jabe ini memiliki daya tarik atau keunikan tersendiri bagi para wisatawan yang berkunjung.

\section{Penginapan Rumah Kurcaci}

Selain rumah panggung di pantai ini juga terdapat penginapan kecil yang biasa di sebut dengan rumah kurcaci. Rumah kurcaci ini berada pinggir pantai jumlahnya ada 5 buah rumah, luas kamar ini tidak lebih dari 2 meter persegi dengan beratap anyaman daun kelapa kering dan dinding dari bambu. Walaupun sederhana rumah kurcaci ini sangat menarik wisatawan lokal ataupun mancanegara untuk menginap ataupun sekedar hanya untuk berfoto di sekitarnya. Tarif menginap di rumah kurcaci ini satu malam $\mathrm{Rp}$ 150.000,00 termasuk morning cake (kue dan teh) untuk 2 orang.

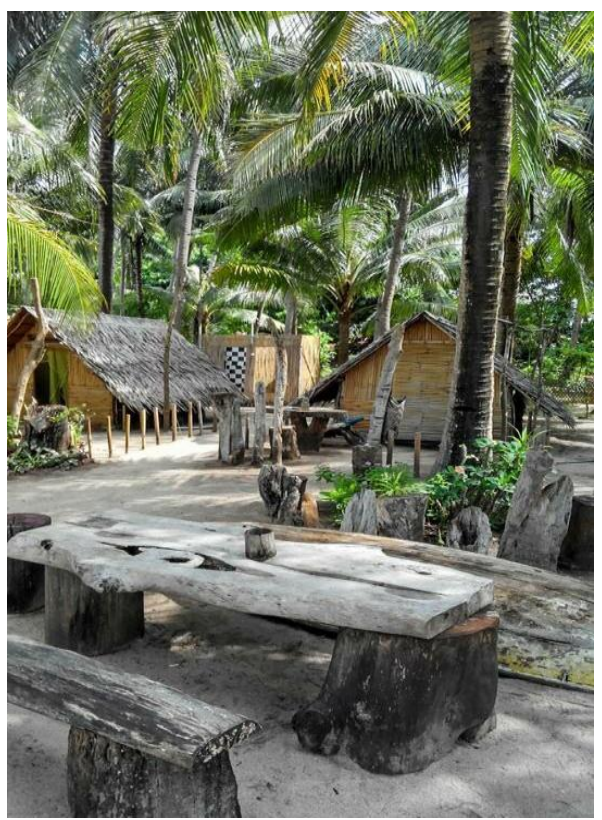

Gambar 4. Penginapan Rumah Kurcaci 


\section{Makanan Khas Suku Bugis}

Menu atau makanan yang di sediakan di Pantai Bunga Jabe ini sangat menarik dan khas yaitu makanan tradisional khas Bugis. Selain makanannya yang khas dalam penyajian makanannya juga sangat menarik. Mulai dari tempat penyajiannya yang biasanya menggunakan piring rotan dengan daun pisang, dan cara penyajiannya biasanya dalam satu nampan besar terdapat beberapa jenis makanan dalam piring-piring kecil. Makanan khas bugis ini menjadi salah satu daya tarik wisata bagi wisatawan lokal maupun mancanegara, selain itu juga menjadi salah satu upaya pelestarian budaya suku bugis yang di lakukan oleh pengelola Pantai Buga Jabe agar adat istiadat, suku dan budayanya tidak tergerus di era perkembangan jaman yang modern ini. Makanan tradisional khas Bugis ini sangat bervariasi dan untuk harga sangat terjangkau. Mulai dari olahan ikan, ayam, sayuran dan beberapa jenis kue atau kudapan semua tersedia disini. Beberapa menu makanan khas bugis yang tersedia di pantai Bunga Jabe adalah Buras, Gogos, Tumbuk, Lepek-lepek, Jejabuk, Gagapek, Bale nasu, Nasu santang, Ikan bakar, Pepes, Tapa ombang, Sayur asam, Lawak lato, Lawak cappak otti, Bingkak, Surabeng, Darlok, Putri sellek, Burongko, Buroncong, Cucur telok, Pisang ijo.

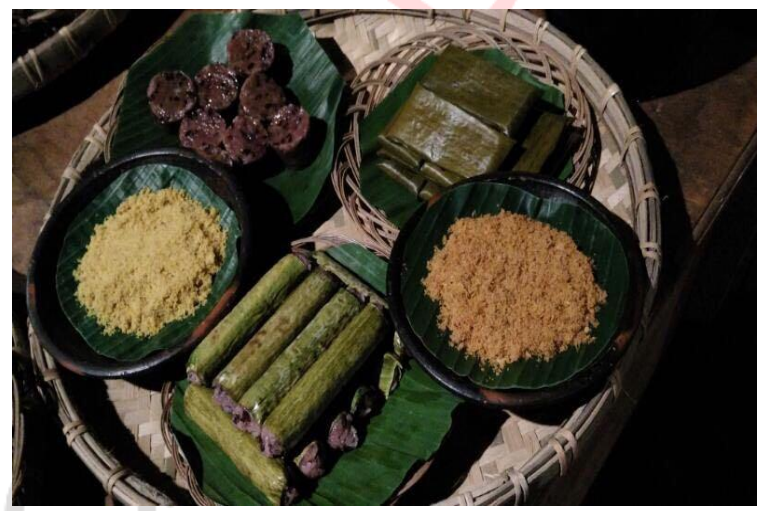

Gambar 5. Makanan Khas Bugis

\section{Upaya Melestarikan Budaya Suku Bugis Dan Lingkungan}

Pengelola menyadari bahwa sumber daya alam, budaya dan potensi yang ada merupakan daya tarik wisata yang harus di jaga kelestariannya, karena daya tarik wisata tersebut menjadi sumber utama untuk mendatangkan wisatawan. Sehingga beberapa upaya yang di lakukan pihak pengelola untuk melestarikan budaya dan lingkungan antara lain:

1. Menanamkan rasa cinta budaya terhadap anak-anak sejak dini dengan cara membiasakan komunikasi setiap hari dengan menggunakan bahasa bugis, memberikan pelatihan tentang kesenian budaya suku bugis seperti tari paduppa dan pecak silat baruga.

2. Dalam setiap acara adat pernikahan, memperingati hari orang meninggal, khataman Al Quran ataupun acara yang lain masyarakat sekitar selalu menghidangkan makanan khas suku bugis tanpa menghilangkan pakempakemnya.

3. Menyediakan akomodasi, makanan dan minuman khas bugis kepada wisatawan.

4. Memanfaatkan sampah laut menjadi karya seni yang indah.Salah satu contoh sampah laut yang di jadikan sebagai karya seni yang indah sehingga cukup menarik perhatian wisatawan adalah kelapa kering yang di pahat atau di bentuk seperti topeng.

5. Menanamkan kepada masyarakat untuk perduli terhadap lingkungan mulai dari hal kecil tidak membuang sampah sembarangan.

6. Sebelum wisatawan melakukan snorkeling di laut pemandu selalu mengingatkan kepada wisatawan ketika breafing untuk tidak membuang 
sampah di laut dan tidak menginjak atau menyentuh karang.

\section{KESIMPULAN DAN REKOMENDASI Kesimpulan}

Dalam pembahasan penelitian tentang Budaya Suku Bugis Sebagai Daya Tarik Wisata Di Pantai Bunga Jabe Karimunjawa dapat di tarik kesimpulan bahwa di Pantai Bunga Jabe terdapat beberapa Budaya Suku Bugis yang di jadikan sebagi daya tarik wisata:

1. Bahasa daerah (bahasa bugis).

2. Kesenian suku bugis yaitu pencak silat baruga dan tari paduppa.

3. Rumah adat suku bugis (rumah panggung).

4. Rumah kurcaci sebagai penginapan.

5. Makanan khas suku bugis.

Tujuan pengelola mengusung atau mengemas konsep budaya suku bugis sebagai daya tarik wisata di Pantai Bunga Jabe Karimunjawa adalah untuk mengenalkan budaya suku bugis terhadap masyarakat luas, selain itu juga sebagai upaya suku bugis untuk melestarikan budayanya agar tidak punah seiring berkembangnya jaman.

Selain itu pengelola juga melakukan upaya agar budaya dan lingkungan tetap terus terjaga kelestariannya dengan cara:

a. Menanamkan rasa cinta budaya terhadap anak-anak sejak dini.

b. Melestarikan makanan khas suku bugis.

c. Menyediakan akomodasi, makanan dan minuman khas bugis kepada wisatawan.

d. Memanfaatkan limbah menjadi karya seni yang indah.

e. Menanamkan kepada masyarakat untuk perduli terhadap lingkungan. f. Menanamkan kepada wisatawan untuk perduli terhadap lingkungan dengan tidak merusaknya.

\section{Rekomendasi}

Dalam penelitian inipeneliti memperoleh hasil temuan tentang budaya suku bugis yang bisa dijadikan sebagai daya tarik wisata dan upaya yang sudah di lakukan pengelola dalam melestarikan budaya serta lingkungan di sekitar Pantai Bunga Jabe Karimunjawa. Oleh karena itu peneliti mengajukan beberapa rekomendasi kepada pihak pengelola untuk meningkatkan daya tarik wisata, keberlanjutan sumber daya alam, budaya dan lingkungan sekitar Pantai Bunga Jabe Karimunjawa. Rekomendasi yang dapat di aplikasikan berdasarkan temuan peneliti:

1. Membuat papan dinding untuk di tuliskan tentang sejarah Pantai Bunga Jabe agar wisatawan bisa mengetahui tentang sejarah awal mula berdirinya Pantai Bunga Jabe hingga saat ini. Karena sejarah atau (history)bisa menjadi sebuah daya tarik wisata yang sangat menarik bagi wisatawan.

2. Pembuatan penunjuk arah ke Pantai Bunga Jabe yang menarik dan jelas.

3. Penambahan fasilitas seperti mushola.

4. Memberdayakan masyarakat lokal untuk pengelolaan Pantai Bunga Jabe.

5. Selalu memperhatikan keberlangsungan atau kelestarian lingkungan, alam dan budaya ketika melakukan pengembangan pariwisata di Pantai Bunga Jabe Karimunjawa ini.

\section{DAFTAR PUSTAKA}

Damanik, Janianton dan Helmut F. Weber. 2006. Perencanaan Ekowisata. Yogyakarta: Andi Offset.

Hadiwijoyo, Suryo. 2012. Perencanaan Pariwisata Perdesaan Berbasis 
Masyarakat (Sebuah Pendekatan

Konsep). Yogyakarta. Graha Ilmu.

Marpaung, Happy. 2002. Pengetahuan

Pariwisata. Bandung. Alfabeta.

Moeleong, Lexy J.2006. Metode Penelitian

Kualitatif. Bandung. PT. Remaja Rosda Karya.

Pendit, Nyoman S. 2006. Ilmu Pariwisata. Jakarta. Pradnya Paramita.

Spillane, James J. 2001. Ekonomi Pariwisata, Sejarah, dan Prospeknya. Yogyakarta. Kanisius.

Sugiyono. 2011. Metode Penelitian

Kuantitatif, Kualitatif dan $R \& D$.

Bandung. Alfabeta.

Undang-Undang Nomor 10 Tahun 2009 Tentang Kepariwisataan.

Yoeti, Oka A. 2006. Pariwisata Budaya. Jakarta. Pradnya Paramita.

Yoeti, Oka A.2002. Perencanaan Strategis Pemasaran Daerah Tujuan Wisata. Jakarta. Pradnya Paramita. 